\title{
An epidemiological study of rheumatic fever and rheumatic heart disease in Lagos
}

\author{
O. OGUNBI, H. O. FADAHUNSI, I. AHMED, A. ANIMASHAUN, \\ S. O. DANIEL, D. U. ONUOHA, AND L. Q. O. OGUNBI
}

From University of Lagos College of Medicine, Lagos, Nigeria

SUMMARY In Lagos 12755 schoolchildren aged between six and 12 years were screened for evidence of rheumatic heart disease and showed a prevalence rate of $0.03 \%$. Group $\mathrm{C}(27.7 \%)$ and group G $(47.3 \%)$ predominated in the throat and in cases of pharyngitis, while group A predominated on the skin. Two hundred and sixty-six cases of pharyngitis were recorded, $70(26.4 \%)$ were positive for $\boldsymbol{\beta}$-haemolytic streptococci. Half of the cases of streptococci were caused by group A $\boldsymbol{\beta}$-haemolytic streptococci while $28.2 \%$ and $21 \cdot 1 \%$ were caused by groups $C$ and $G$ respectively. A diversity of serotypes of group A streptococci, which included types 49 and 55, and $C$ and $G$ streptococci were isolated from impetiginous skin lesions. The main point of interest is the association of group $\mathrm{C}$ and $\mathbf{G}$ streptococci with sore throat and skin infections. The pathogenicity of $\mathrm{C}$ and $\mathbf{G}$ in such circumstances merits further investigation. The present study also showed that prophylactic benzathine penicillin (Penadur) given to patients with rheumatic heart disease or rheumatic fever had been effective with no recurrent attack of acute rheumatic fever.

Until recently it was generally thought that streptococcal infections and their sequelae occurred rarely in tropical and subtropical areas and were not therefore a major problem (Von Bormann quoted by Rotta and Schleifer, 1974). Trowell (1960) indicated that little was known about the natural history of rheumatic fever in Africa. However, Shaper (1972) stated that there was now abundant evidence from studies on hospital inpatients that rheumatic heart disease was today the commonest form of heart disease in children and young adults in most tropical or developing countries and was one of the most common cardiovascular diseases in adults.

Thus, rheumatic fever and rheumatic heart diseases are serious health problems in developing countries and appear to be increasing (Antia et al., 1971). Poor environmental hygiene, low socioeconomic standards, and the lack of a comprehensive prophylactic programme against streptococcal infections are among the contributing factors resulting in this increase.

Classical studies of the streptococcus showed that the throat was the main site of infection, but recently attention has been drawn to the skin as a common site of invasion by streptococci (Dudding et al., 1970; Sharrett et al., 1971; Dillon, 1972).

In a recent study Ogunbi (1971) and Taplin et al. (1973) found that streptococcal pyoderma was very common in a number of tropical countries, with group A streptococci responsible for over $90 \% \frac{2}{3}$ of the infections.

Simon et al. (1965) first drew attention to post streptococcal epidemic nephritis in Trinidad which often followed a primary streptococcal skin lesion.

In view of this evidence of high rates of streptococcal infections in the tropics it was decided:

To determine the prevalence of streptococci in the nose, throat, and skin in the Lagos area

To identify the serotype of streptococci associated with streptococcal infections

To determine the prevalence of rheumatic fever and rheumatic heart disease in the study population

To evaluate the measures aimed at preventing the non-suppurative sequelae of streptococcal infection, particularly rheumatic fever and rheumatic heart disease, in the community.

\section{Materials and methods}

Interest in streptococcal infections began in $1970 \frac{7}{0}$ when a research team started to survey a general population in Lagos for prevalence of streptococci. N The team comprised a medical microbiologist, a paediatric cardiologist, a community physician, $\mathcal{N}$ some junior doctors, health sisters, laboratory $\omega$ technicians, and interview laboratory attendants. The study began by surveying a random sample of 
metropolitan Lagos.

In 1972 there was a second survey (1/10 sample) covering 12755 children aged between six and 12 years from the primary school in Lagos. The schoolchildren were screened for evidence of rheumatic heart disease by medical students in their final year and by resident medical staff working with the team.

The surveillance for rheumatic fever and rheumatic heart disease began in 1973 and effectively covered children attending Massey Street Children's Hospital, Lagos University Teaching Hospital, Lagos City Council Welfare Centres, and School Health Clinics. It continued throughout 1973 and 1974.

The study included an evaluation of secondary prophylactic measures using benzathine penicillin (Penadur) injection for identified cases of rheumatic fever and rheumatic heart disease. These patients were seen regularly on Wednesday afternoons.

There were detailed bacteriological, serological, and clinical follow-up visits of some 380 children randomly selected from the 1972 survey and of 70 cases of pharyngitis from the school population under study for a period of three years.

Biological studies of a few strains of serogroups C and G streptococci isolated from our study population were undertaken by assessing the production of (deoxyribonuclease) DNAse B, hyaluronidase, streptolysin $\mathrm{O}$, and $\mathrm{M}$-associated protein (MAP) (Widdowson et al., 1971); bactericidal tests (Maxted, 1956) were carried out with human donors.

\section{Results}

Table 1 shows that out of the 12755 schoolchildren in Lagos examined in 1972, $1679(13.3 \%)$ were positive throat carriers of streptococci. Of the serogroups identified almost half $(47 \cdot 3 \%)$ were serogroup $\mathbf{G}$, about one-quarter of the cases were serogroup $A(22 \cdot 8 \%)$, and one-quarter serogroup C $(27 \cdot 7 \%)$.

The number of positive skin carriers identified in this population was much lower. Among 154 children who were positive skin carriers there were $58(37.7 \%)$ with identified organisms from the ankle, $35(22 \cdot 7 \%)$ from the back, and $61(39 \cdot 6 \%)$

Table 1 Throat streptococci carriers in schoolchildren in Lagos, 1972

\begin{tabular}{|c|c|c|c|c|c|}
\hline $\begin{array}{l}\text { No. of children examined } \\
\text { No. of positive throat carriers } \\
\text { Prevalence ratio ( } \%)\end{array}$ & & $\begin{array}{l}755 \\
679 \\
13 \cdot 3\end{array}$ & & & \\
\hline $\begin{array}{l}\text { Serogroups } \\
(\%)\end{array}$ & $\underset{47 \cdot 3}{G}$ & $\underset{27 \cdot 7}{C}$ & $\underset{22 \cdot 8}{A}$ & $\underset{0 \cdot 1}{B}$ & $\underset{0 \cdot 9}{D}$ \\
\hline
\end{tabular}

from the wrist. The pattern of serotypes identified from these skin carriers, however, was very different from that of the throat carriers; of the 154 organisms identified from the skin $117(76 \%)$ were serotype A, $26(17 \%)$ were type $G$, and 11 (7\%) were type C. The details are shown in Table 2.

Table 2 Skin streptococci carriers in 12755 schoolchildren in Lagos, 1972

\begin{tabular}{lllll}
\hline & \multicolumn{4}{l}{ Site of positive swabs } \\
\cline { 2 - 5 } & Ankle & Back & Wrist & Total \\
\hline No. of strains & 58 & 35 & 61 & 154 \\
Prevalence ratio (\%) & 0.45 & 0.27 & 0.48 & $1 \cdot 21$ \\
Serogroups & 42 & 26 & 49 & 117 \\
A & 4 & 4 & 3 & 11 \\
G & 12 & 5 & 9 & 26 \\
\hline
\end{tabular}

Table 3 shows that in the study of schoolchildren in Lagos 5300 were examined for skin infections and 724 cases of pyoderma were identified, giving a prevalence ratio of $13.7 \%$. Out of these 724 cases, $402(55.5 \%)$ yielded $\beta$-haemolytic strains of streptococci. The serogroups were A $(89.5 \%)$, G $(6.4 \%)$, C (2.9\%), and $\mathrm{D}(0.9 \%)$.

Table 3 Skin infections in schoolchildren in Lagos, 1972

\begin{tabular}{|c|c|c|}
\hline $\begin{array}{l}\text { No. of children examined } \\
\text { No. of children with pyoderma } \\
\text { Prevalence ratio of pyoderma ( } \%) \\
\text { Total } \beta \text {-haemolytic streptococcal strains } \\
\text { Percentage of pyoderma caused by } \\
\text { B-haemolytic streptococci }\end{array}$ & $\begin{array}{l}5300 \\
724 \\
13 \cdot 7 \\
402 \\
55 \cdot 5\end{array}$ & \\
\hline $\begin{array}{l}\text { Serogroups }(\%) \\
\stackrel{\text { A }}{\mathbf{C}} \\
\mathbf{G} \\
\mathbf{D}\end{array}$ & $\begin{array}{r}360 \\
12 \\
26 \\
4\end{array}$ & $\begin{array}{r}89.5 \% \\
2.9 \% \\
6.4 \% \\
0.9 \%\end{array}$ \\
\hline
\end{tabular}

In the total population of 12755 schoolchildren in Lagos examined in 1972, four $(0.03 \%)$ were found to have previously undetected rheumatic heart disease. Seven cases were already known and identified in the hospital, giving a true prevalence of $0.08 \%$.

In the continuing surveillance study of patients with rheumatic fever or rheumatic heart disease, 53 cases ( 21 males and 32 females) were admitted to the study including the four cases identified in the 1972 survey of schoolchildren. Six $(11 \%)$ were between the age of three and five years, $35(66 \%)$ were between the age of six and 10 years, seven $(13 \%)$ were between 11 and 15 , and five $(10 \%)$ were over the age of 15 years. Of the 53 cases, 42 had clinical signs of valvular lesions, 37 had evidence of acute rheumatic fever, and 22 had congestive 
heart failure. The types of valvular lesions are shown in Table 4.

Table 4 Cases of valvular heart disease seen in surveillance clinics 1973-74

\begin{tabular}{lr}
\hline Mitral incompetence and mitral stenosis & 9 \\
Mitral incompetence & 26 \\
Mitral stenosis & 1 \\
Mitral incompetence and aortic stenosis & 1 \\
Mitral incompetence and aortic incompetence & 4 \\
Mitral incompetence, aortic stenosis, and aortic incompetence & 1 \\
& 42
\end{tabular}

Of these 53 cases a definite history of previous streptococcal throat infection was obtained in only two cases, while such an infection was suspected or probable in 10 cases, and in the remainder it was not possible to obtain a history of such an infection.

Thirty-five patients (14 males and 21 females) attended the clinic for secondary prophylactic benzathine penicillin injections for a period of three years. The dose given was 600000 units every three weeks for children and 1200000 units three weekly for adults. Of these 35 patients, 17 $(48 \%)$ attended the clinic on every occasion, $10(29 \%)$ attended at least $80 \%$ of the time or needed some home visits to encourage attendance, and eight $(23 \%)$ attended less than $80 \%$ of the time despite home visits by the health sister.

In the study of cases of pharyngitis detected at school health clinics in 1973-74, there were 266 cases identified. Seventy-one $(26 \%)$ of these were positive for $\beta$-haemolytic streptococci and half of these, $35(49 \%)$, were serogroup A, about onequarter $20(28 \%)$ were serogroup C, and one-fifth $15(21 \%)$ group G. Eleven of these patients were bled so that ASO titres might be estimated, and the results are shown in Table 5.

In the Lagos University Teaching Hospital 31 cases of active rheumatic fever and 38 cases of rheumatic heart disease were admitted between 1965 and 1974. The distribution of these cases by sex and age is shown in Tables 6 and 7.

Table 5 Patients from the school health clinics who were bled and had ASO titres determined

\begin{tabular}{|c|c|c|}
\hline Case No. & ASO & Isolates \\
\hline $\begin{array}{r}1 \\
2 \\
3 \\
4 \\
5 \\
6 \\
7 \\
8 \\
9 \\
10 \\
11\end{array}$ & $\begin{array}{l}564 \\
564 \\
141 \\
141 \\
564 \\
282 \\
141 \\
282 \\
141 \\
282 \\
181\end{array}$ & 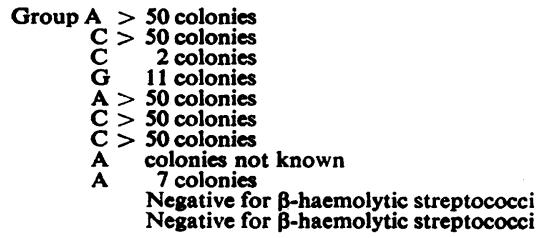 \\
\hline
\end{tabular}

Table 6 Rheumatic fever in Lagos University Teaching Hospital, 1965-74. Distribution in relation to age and sex

\begin{tabular}{|c|c|c|c|}
\hline \multirow{2}{*}{ Age (years) } & \multicolumn{2}{|l|}{ Sex } & \multirow{2}{*}{ Total } \\
\hline & Male & Female & \\
\hline $\begin{array}{r}1-4 \\
5-9 \\
10-14 \\
15-24 \\
25-34\end{array}$ & $\begin{array}{r}2 \\
3 \\
7 \\
0 \\
-\end{array}$ & $\begin{array}{r}1 \\
9 \\
7 \\
2 \\
-\end{array}$ & $\begin{array}{r}3 \\
12 \\
14 \\
2 \\
-\end{array}$ \\
\hline All ages & 12 & 19 & 31 \\
\hline
\end{tabular}

Table 7 Rheumatic heart diseases in Lagos University Teaching Hospital, 1965-74. Distribution in relation to age and sex

\begin{tabular}{llll}
\hline \multirow{2}{*}{ Age (years) } & \multicolumn{2}{l}{ Sex } & Total \\
\cline { 2 - 3 } & Male & Female & \\
\hline $1-4$ & 2 & 1 & 3 \\
$5-9$ & 2 & 5 & 7 \\
$10-14$ & 2 & 4 & 6 \\
$15-24$ & 3 & 5 & 8 \\
$25-34$ & 3 & 4 & 7 \\
$35-44$ & 1 & 3 & 4 \\
$45+$ & - & 3 & 3 \\
All ages & 13 & 25 & 38 \\
\hline
\end{tabular}

\section{Discussion}

We have identified and followed-up 53 cases of rheumatic heart disease since 1973 at our special Streptococcal Disease Clinic. The following clinical features were present in order of magnitude: apical systolic murmur, carditis, fever, and polyarthritiso A history of streptococcal throat infection was not common; rheumatic nodules were rareo erythema marginatum was difficult to see in dark skins; skin infections were not uncommon.

The diagnosis of rheumatic heart disease was easily made at the various clinics and hospitals. The same however cannot be said of rheumatic fever. We presume most of these cases are missed and treated for some other conditions.

Our survey of 12755 children aged between six and 12 years found only four $(0.03 \%)$ cases of previously undetected rheumatic heart disease, but the true prevalence in this population includes not only these four cases but also all those cases drawn from this population who were already known to have been diagnosed as rheumatic heart disease. In Algeria, in a pilot study of an area with a general population of 45000 inhabitants, $0.3 \%$ sought medical care for rheumatic fever and rheumatic heart disease, while in Egypt in a field study of schoolchildren aged between six and 12 years, a prevalence rate of $1 \%$ was found (Strasser and Rotta, 1973).

The low prevalence of a past history of rheumatic fever in Nigeria may be owing to many factors among which are customs, ignorance, traditional beliefs, and low socioeconomic status of most of the population (Antia et al., 1971). 
It is interesting to note that rheumatic fever was seen at ages under five years in our study while the peak incidence of rheumatic heart disease in our community is between five and 10 years. This observation is similar to a Ugandan study in which rheumatic fever and rheumatic heart disease had a peak incidence at between six and 12 years (D'Arbela et al., 1974). However, these peak data differ slightly from the review on the Lagos University Teaching Hospital, as shown in Tables 5 and 6. Benzathine penicillin (Penadur) given to patients with rheumatic heart disease or rheumatic fever was effective (World Health Organisation, 1966) and there has been no recurrent attack of acute rheumatic fever. These findings agree with those of a study at Ibadan, Nigeria (Antia et al., 1971).

We continue to see a preponderance of groups $C$ and $G$ B-haemolytic streptococci among the throat carriers and in cases of pharyngitis, while group A predominates on the skin.

In a five-year study in Czechoslovakia, Rotta et al. (1966) found group A strains accounted for $86.2 \%$ of the streptococci isolated from patients suffering from streptococcal disease and $62.3 \%$ of the strains from normal carriers.

Christie (1969) stated that $95 \%$ of haemolytic streptococci infections in man are caused by some group A streptococci. The preponderance of groups $\mathbf{C}$ and $\mathbf{G}$ in our community requires further study to elucidate their possible pathogenic roles. Evidence of infection as shown by rise in ASO titre, and primary isolates of over 50 colonies incriminated both serogroups $\mathbf{C}$ and $\mathbf{G}$ as primary pathogens responsible for many cases of pharyngitis in our study. Ninety per cent of streptococcal pyoderms were caused by group $\mathbf{A}$ while groups $\mathbf{C}$ and $\mathbf{G}$ accounted for only $7 \cdot 3 \%$. This finding agrees with that of Taplin et al. (1973) in which over $90 \%$ of cases of streptococcal pyoderma was found to belong to group $\mathrm{A}$.

In our studies we found no evidence of an association of streptococcal pyoderma with rheumatic fever or rheumatic heart disease. Although we have relatively high primary streptococcal infection of the pharynx by groups $C$ and $G$ streptococcal, we have yet to associate either of the two with rheumatic fever or rheumatic heart disease. But this study shows that in a tropical population there is an association between carditis and skin infections from Serogroup A. Continued surveillance to clarify the above situation is necessary.

Reprints from S. O. Daniel, University of Lagos College of Medicine, PM Bag 12003, Lagos, Nigeria.

\section{References}

Antia, U., Effiong, C. E., and Reddy, S. (1971). Rheumatic heart disease in children in developing countries. Ghana Medical Journal, 10, 9-13.

Christie, A. B. (1969). Infectious Diseases: Epidemiology and Clinical Practice, volume 8, p. 972. Williams and Wilkins: Baltimore.

D'Arbela, P. G., Patel, A. K., and Somers, K. (1974). Juvenile rheumatic fever and rheumatic heart disease at Mulago hospital, Kampala, Uganda: Some aspects of the pattern of the disease. East African Medical Journal, 61, 710-714.

Dillon, H. C. (1972). Streptococcal infections of the skin and their complications: Impetigo and nephritis. In Streptococci and Streptococcal Diseases, pp. 572-586. Edited by L. W. Wannamaker and J. M. Natsen. Academic Press: New York.

Dudding, B. A., Burnett, J. W., Chapman, S. S., and Wannamaker, L. W. (1970). The role of normal skin in the spread of streptococcal pyoderma. Journal of Hygiene, 68, 19-28.

Maxted, W. R. (1956). Indirect bacterial test as means of identifying antibody to $\mathbf{M}$-antigen of streptococcus pyogenes. British Journal of Experimental Pathology, 37, 415-422.

Ogunbi, O. (1971). A study of $\beta$-haemolytic streptococci in throats, noses, and skin lesions in a Nigerian (Lagos) urban population. Journal of the Nigerian Medical Association, 1, 159-164.

Rotta, J., Hejnoa, M., Bicova, R., Curik, B., Mickova, S., and Salacova, J. (1966). Surveillance of haemolytic streptococcal group and type (streptococcus pyrogens) distribution over the territory of Czechoslovakia: A five year study. Journal of Hygiene, Epidemiology, Microbiology, and Immunology, 12, 176-186.

Rotta, J., and Schleifer, K. H. (1974). Pyogenic activity of bacterial mucopeptides. Journal of Hygiene, Epidemiology, Microbiology, and Immunology, 18, 50-59.

Shaper, A. G. (1972). Cardiovascular disease in the tropics. I. Rheumatic heart. British Medical Journal, 3, 683-686.

Sharrett, A. R., Poon-King, T., Potter, E. V., Finklea, J. F., and Earle, D. P. (1971). Subclinical nephritis in south Trinidad. American Journal of Epidemiology, 94, 231-245.

Simon, N. S., Potter, E. V., Siegel, A. C., McAninch, J., Poon-King, T., Humair, L., and Earle, D. P. (1965). Epidemic nephritis in Trinidad (abstract). Journal of Laboratory and Clinical Medicine, 66, 1022.

Strasser, T., and Rotta, J. (1973). The control of rheumatic fever and rheumatic heart disease: An outline of WHO activities. World Health Organisation Chronicle, 27, 49-54.

Taplin, D., Lansdell, L., Allen, A. M., Rodriguez, R. and Cortes, A. (1973). Prevalence of streptococcal pyoderma in relation to climate and hygiene. Lancet, 1, 501-503.

Trowell, H. C. (1960). Non-infective Disease in Africa, p. 86. Arnold: London.

Widdowson, J. P., Maxted, W. R., and Pinney, A. M. (1971). An $M$-associated protein antigen MAP of group A streptococcus. Journal of Hygiene, 69, 553-564.

World Health Organisation (1966). Prevention of Rheumatic Fever. Technical Report Series No. 342. WHO: Geneva. 